\title{
BMJ Open Discussions during shared decision- making in older adults with advanced renal disease: a scoping review
}

\author{
Rajesh Raj (D) , ${ }^{1,2}$ Srivathsan Thiruvengadam (D) , ${ }^{3}$ Kiran Deep Kaur Ahuja (D) , ${ }^{4}$ \\ Mai Frandsen (D) ${ }^{5}$ Matthew Jose ${ }^{2,6}$
}

To cite: Raj $R$,

Thiruvengadam S, Ahuja KDK, et al. Discussions during shared decision-making in older adults with advanced renal disease: a scoping review. BMJ Open 2019;9:e031427. doi:10.1136/ bmjopen-2019-031427

- Prepublication history and additional material for this paper are available online. To view please visit the journal (http:// dx.doi.org/10.1136/bmjopen2019-031427).

Received 03 May 2019 Revised 21 October 2019 Accepted 23 October 2019

Check for updates

(c) Author(s) (or their employer(s)) 2019. Re-use permitted under CC BY-NC. No commercial re-use. See rights and permissions. Published by BMJ.

${ }^{1}$ Department of Nephrology, Launceston General Hospital, Launceston, Tasmania, Australia

${ }^{2}$ School of Medicine, University of Tasmania, Hobart, Tasmania, Australia

${ }^{3}$ Nephrology Service, Hammersmith Hospital, London, UK

${ }^{4}$ School of Health Sciences, University of Tasmania, Hobart, Tasmania, Australia

${ }^{5}$ Faculty of Health, University of Tasmania, Launceston,

Tasmania, Australia

${ }^{6}$ Department of Nephrology, Royal Hobart Hospital, Hobart, Tasmania, Australia

Correspondence to

Dr Rajesh Raj;

drrajeshraj@gmail.com

\section{ABSTRACT}

Objectives This review summarises the information available for clinicians counselling older patients with kidney failure about treatment options, focusing on prognosis, quality of life, the lived experiences of treatment and the information needs of older adults.

Design We followed the Joanna Briggs Institute Methodology for Scoping Reviews. The final report conforms to the PRISMA-ScR guidelines.

Data sources PubMed, PsycINF0, CINAHL, Embase, Scopus, Web of Science, TRIP and online repositories (for dissertations, guidelines and recommendations from national renal associations).

Eligibility criteria for inclusion Articles in English studying older adults with advanced kidney disease (estimated glomerular filtration rate $<30 \mathrm{~mL} / \mathrm{min} / 1.73 \mathrm{~m}^{2}$ ); published between January 2000 and August 2018. Articles not addressing older patients separately or those comparing between dialysis modalities were excluded.

Data extraction and synthesis Two independent reviewers screened articles for inclusion and grouped them by topic as per the objectives above. Quantitative data were presented as tables and charts; qualitative themes were identified and described.

Results 248 articles were included after screening 15445 initial results. We summarised prognostic scores and compared dialysis and non-dialytic care. We highlighted potentially modifiable factors affecting quality of life. From reports of the lived experiences, we documented the effects of symptoms, of ageing, the feelings of disempowerment and the need for adaptation. Exploration of information needs suggested that patients want to participate in decision-making and need information, in simple terms, about survival and non-survival outcomes. Conclusion When discussing treatment options, validated prognostic scores are useful. Older patients with multiple comorbidities do not do well with dialysis. The modifiable factors contributing to the low quality of life in this cohort deserve attention. Older patients suffer a high symptom burden and functional deterioration; they have to cope with significant life changes and feelings of disempowerment. They desire greater involvement and more information about illness, symptoms and what to expect with treatment.

\section{INTRODUCTION}

Physicians are uncomfortable about communicating prognosis to seriously ill

\section{Strengths and limitations of this study}

- This review provides an interpretative summary of the information relevant to the shared decisionmaking process around treatment for older adults with end-stage kidney failure-a patient group with increasing numbers worldwide, unclear outcomes from treatment and for whom clinicians struggle to provide appropriate advice.

- The scoping review format, which collects information across a wide range, is relevant as there is a plethora of issues across multiple domains and sources to consider in the older adult. This review summarises information on prognosis, quality of life, lived experience of treatment and specific information needs in older patients.

- In order to preserve focus, this scoping review did not cover some topics relevant to treatment decisions such as the comparison between dialysis modalities (especially modified treatments such as assisted or incremental dialysis) or transplantation, techniques for presenting information or educating patients, or the logistic/financial barriers to treatment. We believe several of these topics require additional, separate reviews. In addition, our exclusion of non-English articles neglects research from some parts of the world.

- While this scoping review presents a wide range of information, it does not grade its quality or study its delivery to the patient; therefore, the use of this information in practice is dependent on the individual clinicians participating in the shared discussions.

patients. ${ }^{12}$ This is also true for nephrologists looking after patients with advanced kidney disease. $^{3-7}$ There is evidence to suggest that patients receive insufficient information or are unrealistically optimistic about their prognosis. ${ }^{89}$ Patients often wish they had received more information prior to commencing dialysis. For instance, they expect their doctors to provide them information about prognosis even without being prompted to do so. ${ }^{10} 11$ Such descriptions highlight the shortcomings often encountered when older patients and their multiprofessional clinical teams 


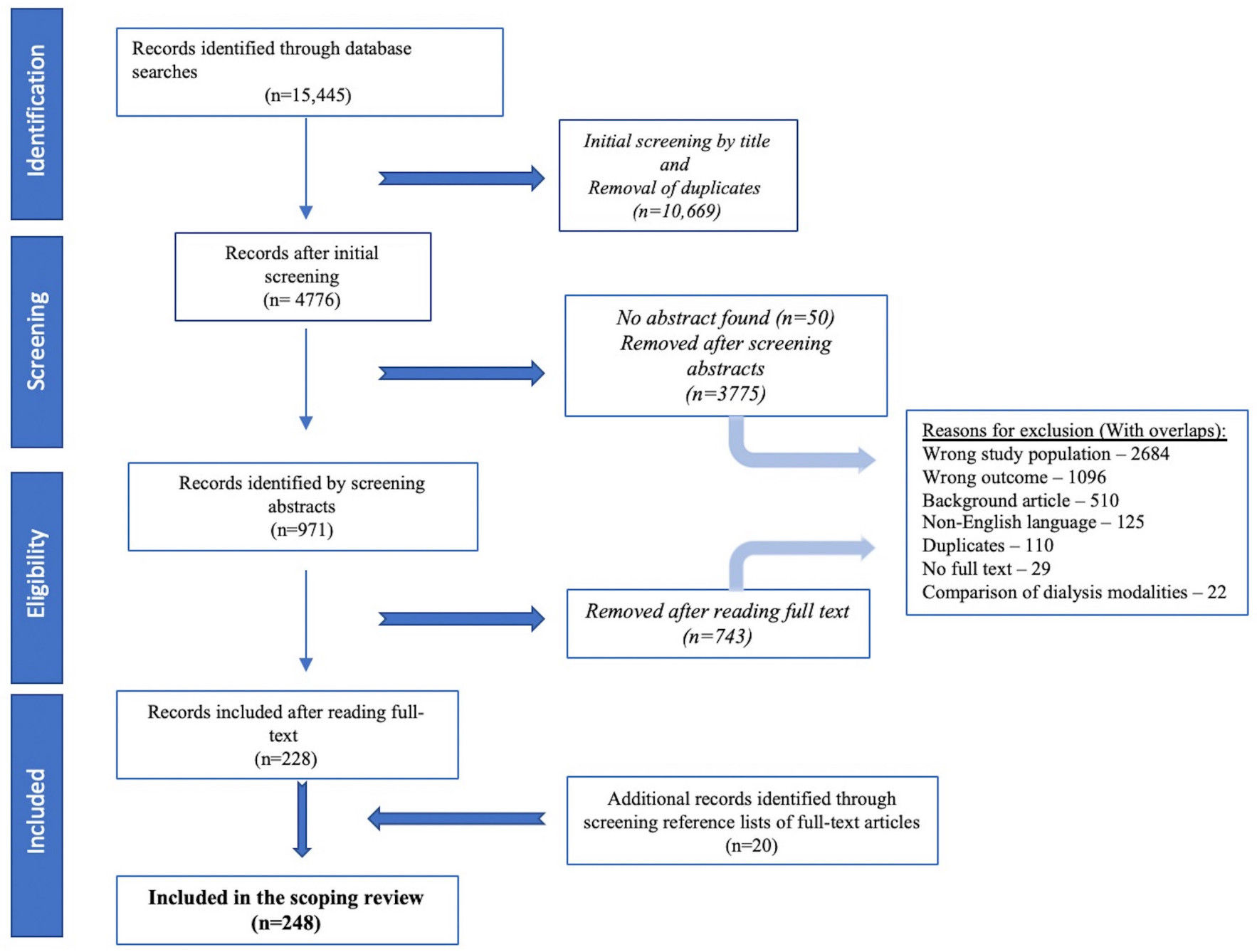

Figure 1 PRISMA flowchart for study inclusion. ${ }^{29}$

(doctors, renal nurses and other allied health personnel) approach the complex decisions about treatment options for advanced kidney disease. ${ }^{12}$

In older patients, the rate of progression of kidney disease may not be as rapid as their younger counterparts. ${ }^{13}$ In addition, in older patients who do progress to end-stage kidney disease, treatment with dialysis, which is the default option, may not always lead to better outcomes or improve quality of life. ${ }^{14} 15$ With this in mind, several nephrology centres across the world now offer a dedicated programme of conservative management or non-dialytic care (ie, holistic patient management that does not include dialysis or transplantation; sometimes called 'supportive care') ${ }^{16-19}$ The current dilemma, for patients and physicians alike, is in deciding which among these two options-dialysis or non-dialytic, conservative management-is ideal for an individual patient. ${ }^{20}$

Professional nephrology associations call on the community to ensure that decisions regarding dialysis, especially in older, sicker adults, be made according to the principles of patient-focused, shared decisionmaking. ${ }^{21} 22$ Open, transparent and complete sharing of information, particularly with regards to prognosis and quality of life, with dialysis treatment or otherwise, is an important part of this process. However, physicians may be handicapped by the lack of appropriate information regarding outcomes of the various forms of treatment in the older population..$^{23}$ Different prognostic instruments that predict renal worsening or survival exist, but while some are rigorously developed and validated, others may not be accurate or ideally developed. ${ }^{24-27}$ There is a perceived paucity of information on outcomes other than survival-such as functional status or quality of life-that are important to patients.

While discussing treatment options with older patients in the shared decision-making process, professionals have to draw on information from different sources (such as prognostic studies, reports of quality of life or experiences of patients already on dialysis), spread across multiple domains, and not easily available in a consolidated form. Such characteristics are well addressed when appraising the literature using the scoping review format, which reports on the breadth of information available in the area, intending to describe the field and uncover any gaps in the literature. We therefore undertook a scoping review to identify and summarise information from the 

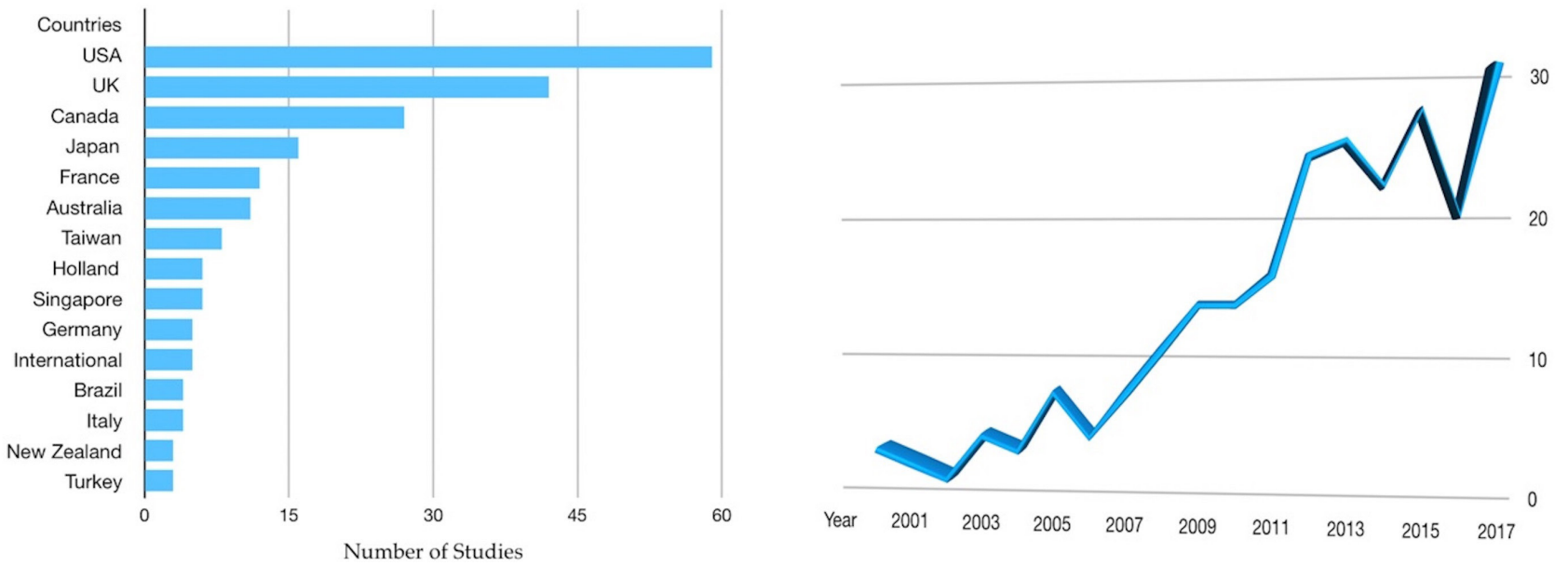

Figure 2 Countries of origin and years of publication of included articles.

published literature that might facilitate the discussions about treatment that multiprofessional healthcare team members conduct with older people who have advanced kidney disease.

\begin{tabular}{|c|c|}
\hline Sociodemographic & Comorbidities/organ \\
\hline Age & function \\
\hline Gender & Number of comorbidities \\
\hline Race & Diabetes \\
\hline Institutionalisation (eg, & Hypertension \\
\hline nursing home) & Dementia \\
\hline Nephrology care & Depression \\
\hline Mode of treatment (dialysis & Visual impairment \\
\hline vs non-dialysis care) & Residual urine \\
\hline Length of renal follow-up & Ejection fraction \\
\hline Hospitalisations & Biochemical tests \\
\hline Elective vs unplanned start & GFR estimated from \\
\hline Related to dialysis & serum creatinine \\
\hline Elective vs unplanned start & Rate of fall of GFR \\
\hline Dialysis access & Urine creatinine \\
\hline Adequacy & Proteinuria \\
\hline Length of session & Albumin \\
\hline Years spent on dialysis & Haemoglobin \\
\hline Functional status & Calcium \\
\hline Self-rated health & Phosphate \\
\hline Frailty & Parathyroid hormone \\
\hline Mobility & $\mathrm{HbA1c}$ \\
\hline Falls & Cholesterol \\
\hline Dependence & C-reactive protein \\
\hline Activities of daily living & Testosterone \\
\hline Bedridden status & Plasma pro-ANP \\
\hline Body composition & P-cresyl sulfate \\
\hline Sarcopenia & Indole sulfate \\
\hline Muscle mass and fat & \\
\hline
\end{tabular}

*Studied individually, or as part of other indices.

GFR, glomerular filtration rate.

\section{METHODS}

The scoping review adhered to the PRISMA-ScR checklist for scoping review conduct and reporting, as detailed in the online supplementary file $1 .^{28}$

\section{Objectives and research questions}

The objective of this review was to identify and summarise the articles providing information relevant to discussions of treatment for advanced kidney disease with older patients. The specific questions for the review were developed after a scan of the literature and discussions with local clinicians and academics. We explicitly included questions that addressed the patient perspective. They were further refined by peer review during publication of the protocol. The objectives, inclusion criteria and methods for this scoping review were specified in a previously published protocol (see online supplementary file 2). ${ }^{29}$

In brief, this scoping review, conducted according to the Joanna Briggs Institute Protocol for Scoping Reviews, sought to address the following questions in the older patient with advanced kidney disease ${ }^{30}$ :

- What are the factors affecting prognosis and survival (with dialysis treatment or with conservative management not including dialysis)?

- Which factors influence the quality of life?

- What information is available regarding the lived experiences with the various treatment pathways?

- What is known about the information needs of this population as they consider treatment options?

The study aimed to synthesise information from quantitative and qualitative literature, with reference to the research questions listed above, so as to

- Provide a coherent summary for clinicians, and

- Explore areas for future research. 


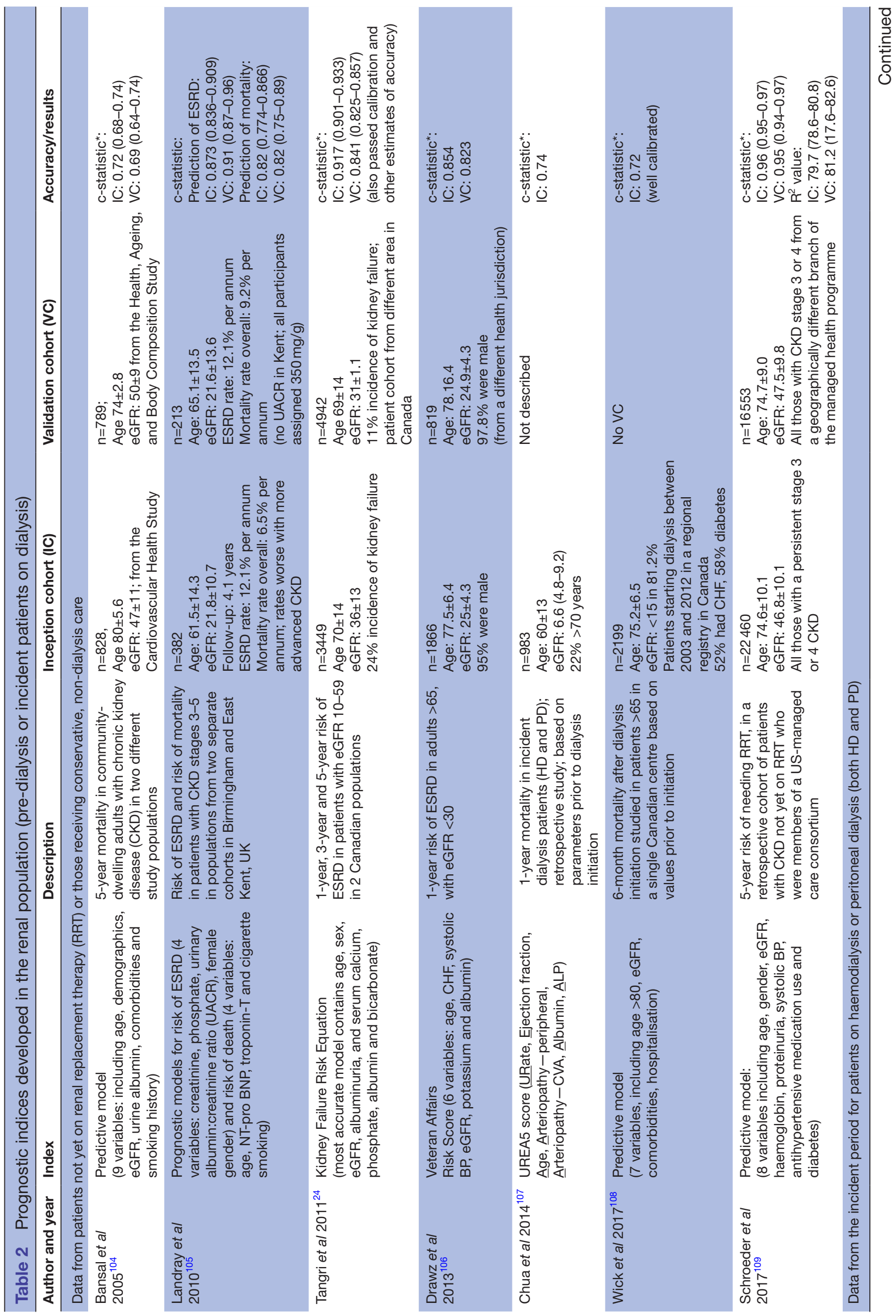




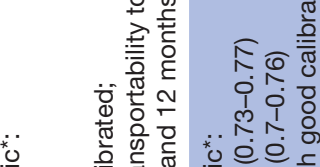

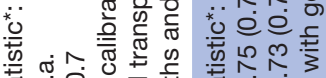

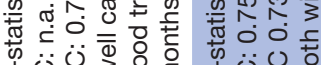

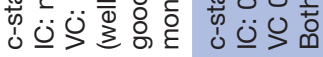

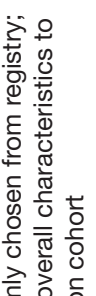

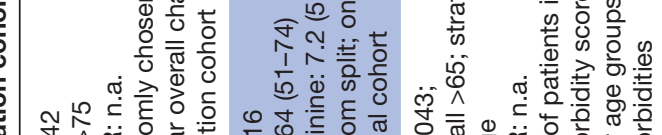

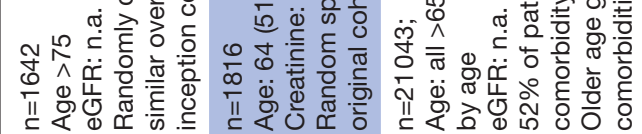

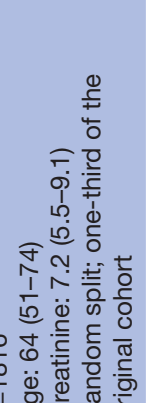

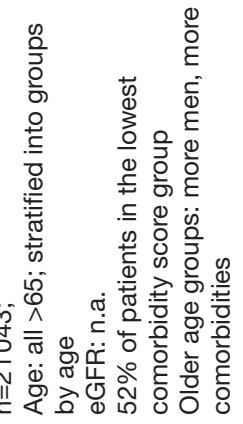

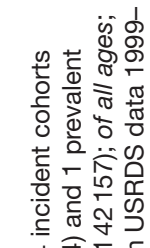

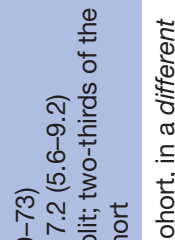

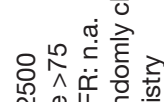

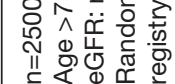

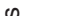

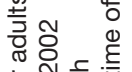

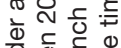

O 这

$\subseteq$ त

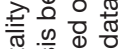

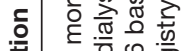

흘

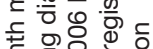

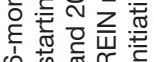

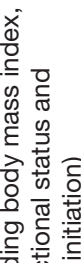

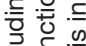

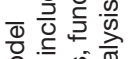

일

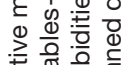

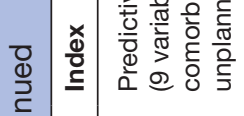

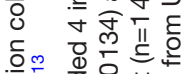

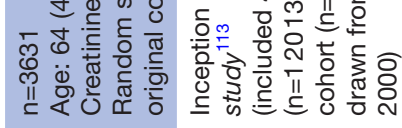

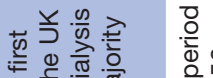

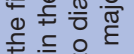

产

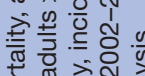

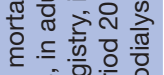

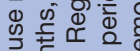

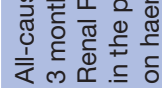

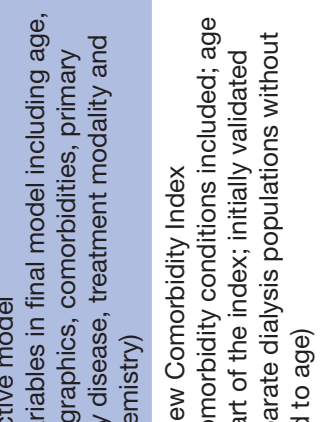

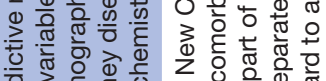

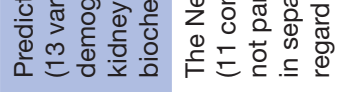

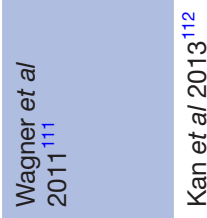

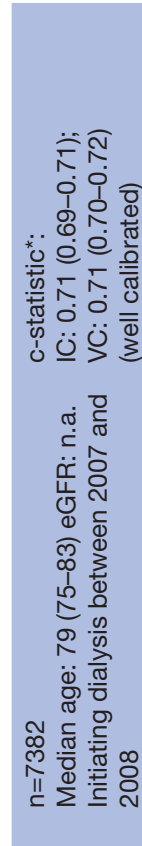

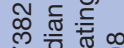

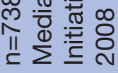

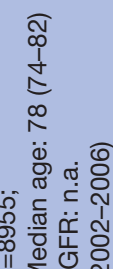

II

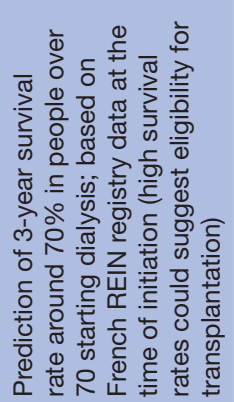

ำ 두을

ì

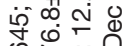

造

빈

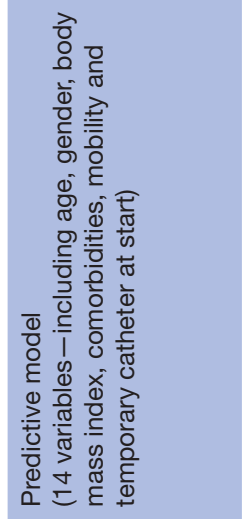

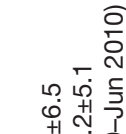

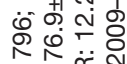

Nิ

닌

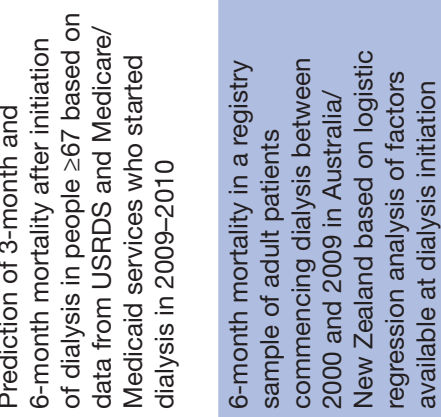

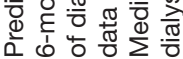
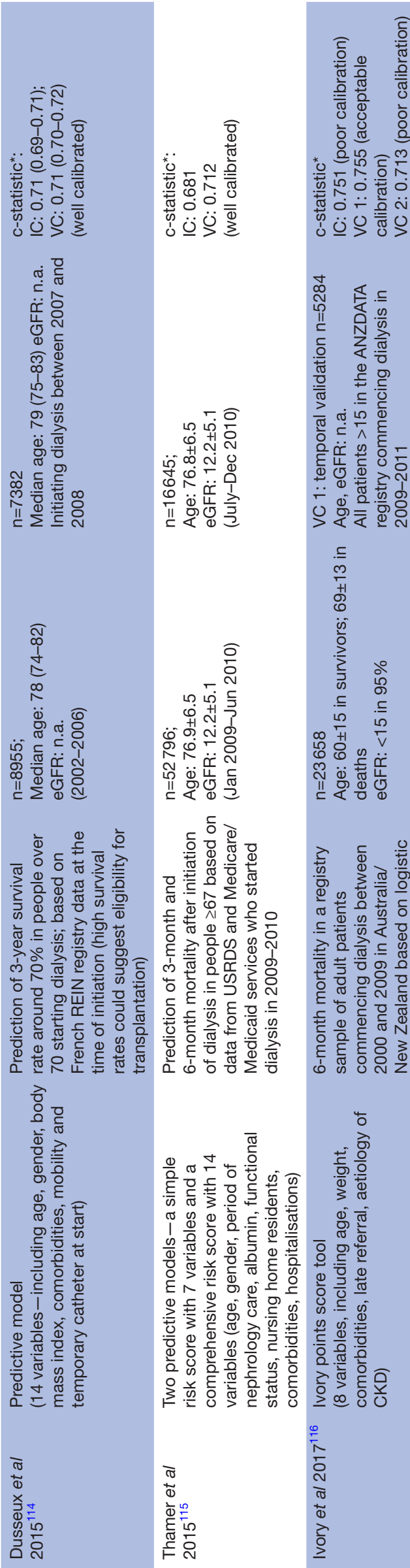

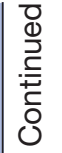




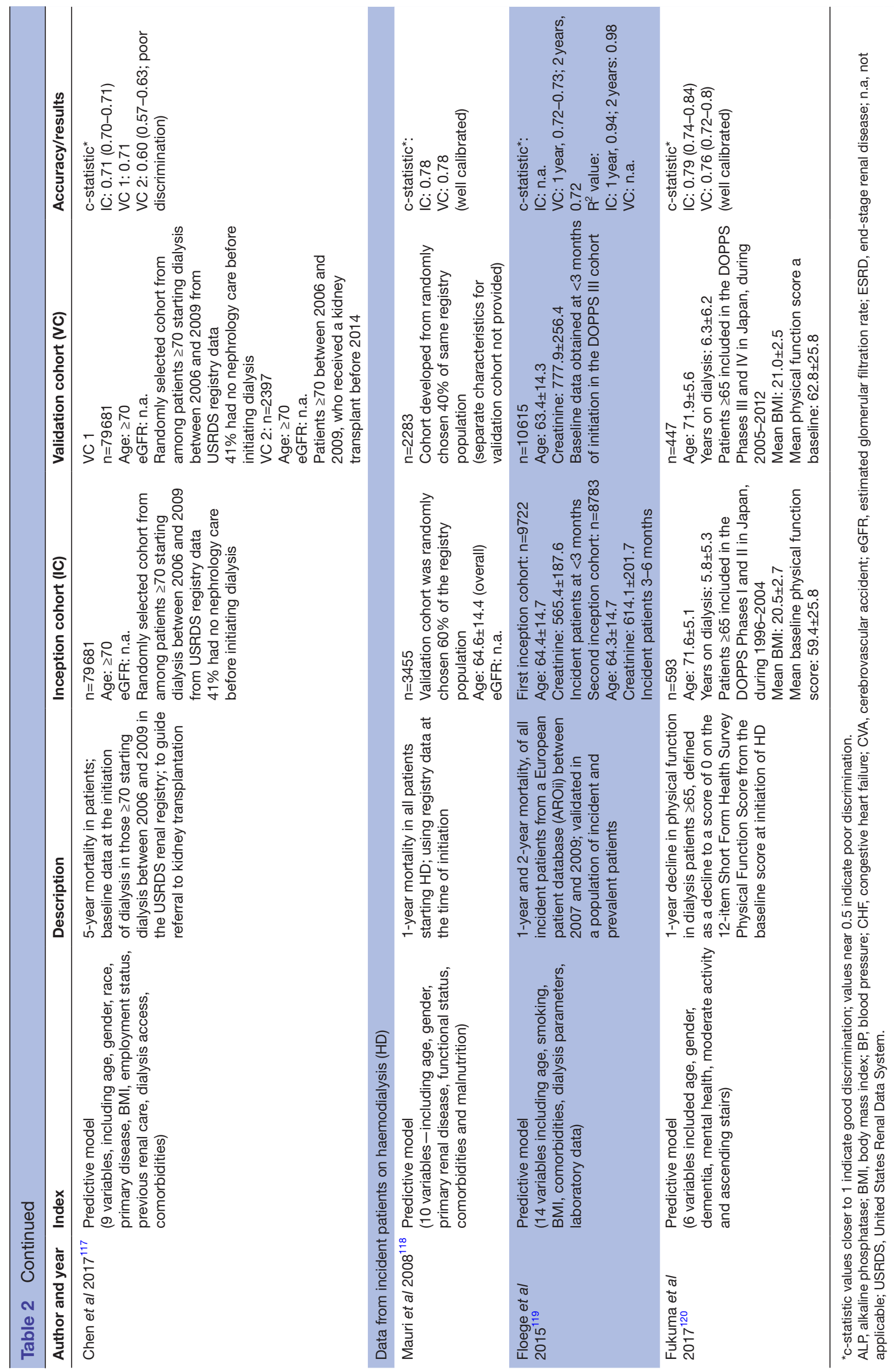




\section{Inclusion criteria}

The scoping review included articles that addressed older adults with advanced kidney disease and focused specifically on survival/mortality, factors affecting prognosis or quality of life, descriptions of the lived experience of treatment (on dialysis or conservative management) or descriptions of the information needs of older adults. These four areas were developed by consensus between the authors after considering the areas of relevance to the dialysis decision.

In order to capture all relevant data, we included all studies where the population studied was described by primary researchers using terms such as 'elderly', 'aged', 'geriatric' or 'older', without pre-specifying an age cut-off to define the older adult. Advanced kidney disease was defined for this review as an estimated glomerular filtration rate $(\mathrm{eGFR}) \leq 30 \mathrm{~mL} / \mathrm{min} / 1.73 \mathrm{~m}^{2}$.

We included articles from the time period of January 2000 to August 2018. This time period was chosen so as to reflect the increasing number of older patients on dialysis, the changing attitudes to the treatment of older adults in recent years and the establishment of conservative care without dialysis as a valid treatment option. All forms of research, involving both quantitative and qualitative methods, and articles that were published in peerreviewed literature as well as the 'grey' literature were included. The focus was on information that was likely to be of value in choosing whether to have dialysis (any type of dialysis) or not. Only articles written in English were included (as we had limited translation resources).

\section{Exclusion criteria}

- Research that did not address older adults (see operational definition above) as the main population or as a subpopulation of interest,

- Research that primarily focused on those with an $\mathrm{eGFR}>30 \mathrm{~mL} / \mathrm{min} / 1.73 \mathrm{~m}^{2}$,

- Research exclusively comparing variations of dialysis treatment modalities or transplantation with each other,

- Research describing the effects of interventions other than dialysis, or

- Research with reports in languages other than English.

\section{Search methodology}

Databases searched included PubMed, Embase, PsycINFO, CINAHL, EbscoHost, Mednar, Cochrane, TRIP databases and Web of Science for peer-reviewed research, and OpenSIGLE, Open Grey, Trove, EThOS, OATD.org and OpenThesis for grey literature. Websites of national specialty societies and clinical guideline collections were also searched. Searched terms included those relevant for older patients, chronic kidney disease, dialysis, conservative management, prognosis, survival, quality of life, lived experiences and information needs. These terms were adapted to suit searches in individual databases; examples of search terms are provided as online supplementary file 3 .
Initial screening of articles was undertaken by two researchers (RR and ST) working independently, using the web-based Rayyan QCRI software (Qatar Computer Research Institute and Qatar Foundation, Qatar). ${ }^{31}$ Charting of included studies and the extraction of relevant information were done using FileMakerPro16 (FileMaker, California, USA) and Microsoft Excel software (Microsoft, Washington, USA). Separate data extraction forms and charting sheets were used for the four different research questions, as shown in the published protocol. ${ }^{29}$ For included articles, the following data were extracted: primary author, year of publication, type of research, modality of treatment studied, population, focus of research and main findings. Forms used for final data extraction are provided as online supplementary file 4 .

\section{Patient and public involvement}

We did not involve patients or members of the public in the design or conduct of this scoping review. However, two of the research questions for the scoping review directly summarised reports of patient experiences and information needs.

\section{RESULTS}

Figure 1 shows the flowchart summarising the selection of studies to be included in this scoping review and the reasons for exclusion. All 15445 articles identified in databases were imported into the reference management software as detailed. Subsequent screening of titles and removal of duplicates provided 4776 articles for review with abstracts. These articles were divided into groups depending on the questions of the survey, and 971 articles used for full-text review. Cohen's kappa for inter-rater agreement between the two reviewers during the initial (blinded) screening of articles for inclusion was 0.54 , suggesting 'moderate' agreement. ${ }^{32}$ Conflicting decisions regarding suitability for inclusion were subsequently resolved by discussion among the authors. Finally, 228 articles were included, along with 20 articles found by hand-searching reference lists of included articles, making up 248 articles selected for analysis (see online supplementary file 5 for list of included studies). This included three theses obtained from screening of the grey literature.

The majority of included articles have primary authors resident in the English-speaking countries-USA, UK, Canada and Australia. Japan, France, Taiwan and Holland were the other significant contributors (figure 2). A greater proportion of research literature was written in the previous 5 years (2012-2017); the number of articles on older patients with kidney failure showed an increasing trend in recent years.

Overall, half the included articles refer to patients on haemodialysis exclusively; $18 \%$ were studies on patients not on dialysis and 5\% included all older patients with end-stage kidney disease, regardless of treatment choice. Peritoneal dialysis patients alone contributed to $8 \%$ of 
studies while $17 \%$ included patients undergoing both peritoneal and haemodialysis.

For purposes of analysis, the included studies were analysed in groups, according to the research questions for the review detailed above (prognosis, quality of life, lived experiences and information needs, respectively). The following section on results is also presented according to these questions.

\section{Characteristics of studies describing prognosis}

In all, 112 articles that specifically focused on the prognosis of the older patient with advanced kidney failure were included in the review. Thirty-four were single-centre studies; 28 involved patients in multiple centres, while 24 studies, often with participant numbers in excess of 1000, were conducted as registry-based research. Sixty-six studies $(61.8 \%)$ were retrospective studies (including 20 out of the 24 registry-based studies). Studies that only included patients on haemodialysis predominated (39 studies).

\section{Content and scope of studies describing prognosis}

Mortality/survival was the the most common prognostic outcome of interest. Other outcomes were also studied, usually in addition to mortality and included quality-of-life outcomes, time to renal replacement therapy/end-stage kidney disease, hospitalisation and functional or nutritional status.

Researchers considered several different variables for inclusion as prognostic markers (table 1 ). The stated aim in several papers was to use easily available, clinical indicators to predict prognosis. Most commonly, researchers used a combination of variables-clinical, laboratory, demographic or instrumentbased data to derive prognosis. These variables could be grouped into sociodemographic variables (including age, nursing home residence), comorbidities, functional status, nutritional parameters, aspects of nephrology or dialysis care, and biochemical variables (see online supplementary file 6 for a detailed list).

A common method was to use a combination of variables in order to predict prognosis. While some studies investigated particular combinations of variables in single cohorts, others reported inception and validation cohorts, presenting the combination of variables as an index or prognostic score. Some of these scores were developed specifically in patients with renal failure, while others were adaptations of prognostic tools used in the general population. Table 2 describes such indices that were developed exclusively in the older patient or use age as a variable in the index to derive prognosis (therefore making them suitable for use in the older population).

We identified 12 studies that compared dialysis treatments with conservative management without dialysis. Table 3 lists these studies, in chronological order, where the older population has been the focus of comparisons between dialysis or conservative management.

Characteristics of studies describing effects on quality of life Eighty studies representing research that evaluated the factors influencing the quality of life in older adults on dialysis were selected. Of these, 29 were clinical research papers, the rest being reviews of related topics or expert opinion. Among the 29 articles reporting on original clinical research, 24 used questionnaires or surveys to interrogate quality of life. The supplementary materials include a list of the commonly used instruments to measure quality of life in elders on dialysis.

\section{Content and scope of articles discussing factors influencing quality of life}

Table 4 lists the factors affecting quality of life, identified from analyses of the included articles. They have been separated into modifiable and non-modifiable factors for convenience.

Age had an impact on quality of life. While physical aspects of quality of life in the elders were low, especially once on dialysis, other aspects of quality of life such as life satisfaction, mental component scores or social wellbeing appeared to be more stable in older than younger patients. 3334

Researchers who compared the quality of life outcomes in older people between the conservatively managed pathway versus the renal replacement pathway reported either no major differences between the two or worse quality of life with dialysis. ${ }^{35-37}$

Psychological factors were relevant to quality of life. Depression scores, spiritual and emotional well-being and even cognitive impairment have been reported to affect quality of life. ${ }^{38}$ Functional impairments and frailty, diminished exercise and impaired activities of daily living all worsened quality of life. Despite diminishing functional status, rates of hospitalisation were not significantly different between older and younger patients on dialysis. ${ }^{40}$ For patients already on dialysis, several dialysis-related factors contributed to quality of life. These included the number of years on dialysis, alterations in dialysis regimes or the duration of dialysis sessions. Finally, other comorbidities such as diabetes, myocardial infarction and stroke worsened quality of life.

\section{Characteristics of studies describing lived experience with advanced kidney disease}

Ninety-four studies that reported on the experiences of older adults living with advanced kidney failure were included. The majority of articles (74 of 94) detailed original clinical research; 23 employed qualitative analysis, usually in the form of interview or focus group analysis, while 29 used a particular tool or instrument to assess one of the aspects of experience. A list of the common instruments used in these studies is provided as online supplementary material, sorted according to the area of analysis.

\section{Content and scope of studies describing lived experience with advanced kidney disease}

Several studies used scores or indices to study life on dialysis; importance is also given to symptoms, functional and cognitive aspects (and, particularly in this age group, to 


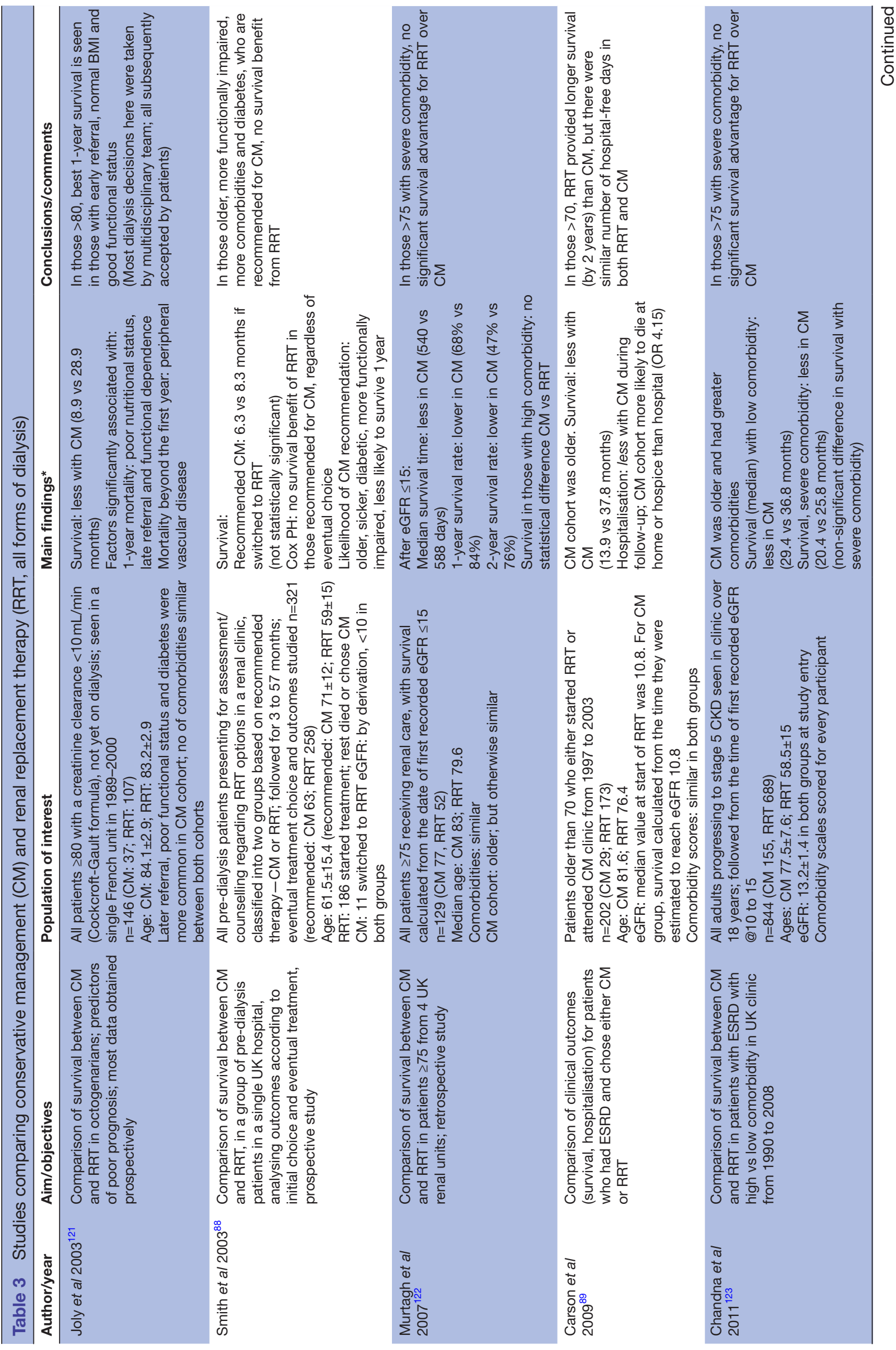




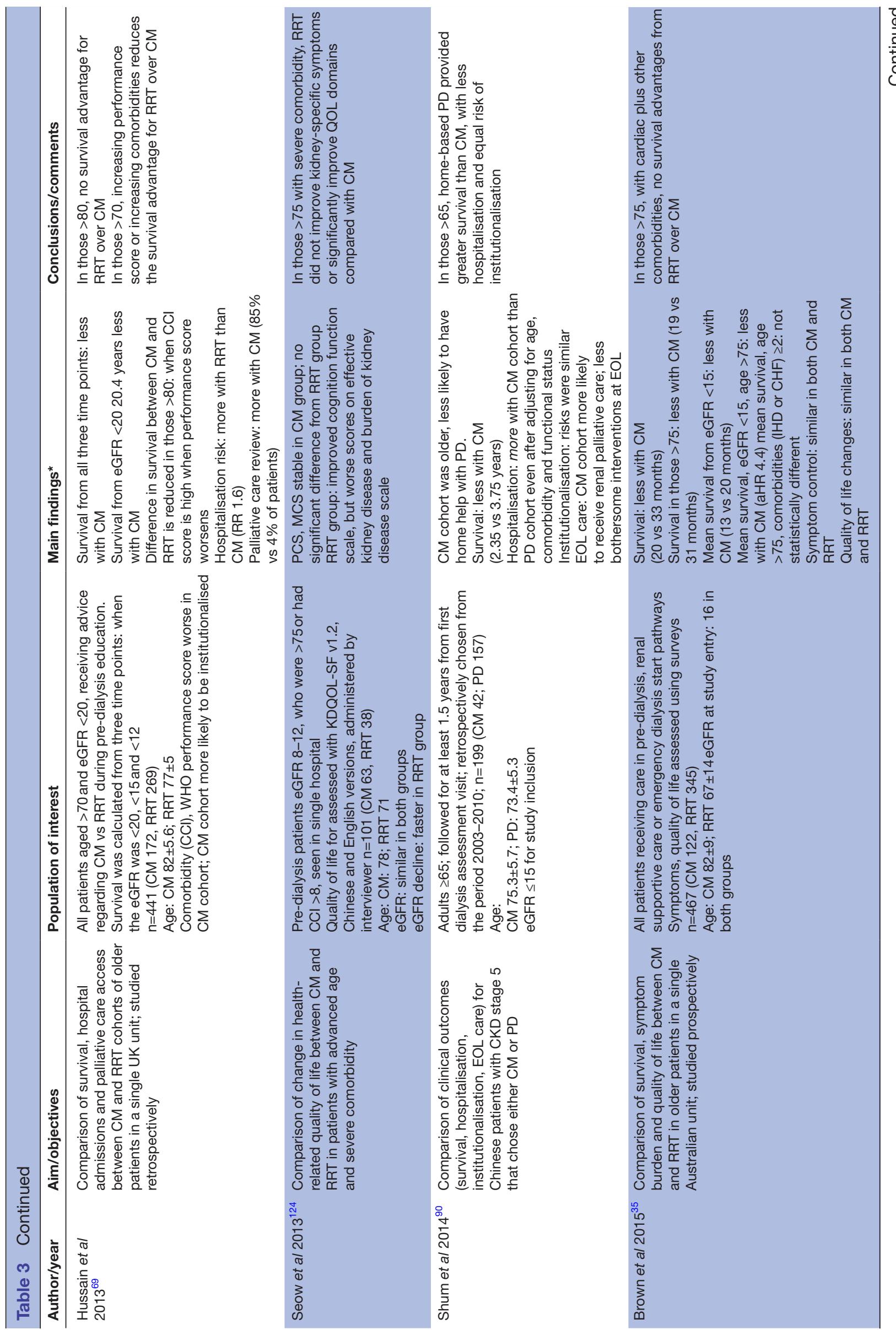




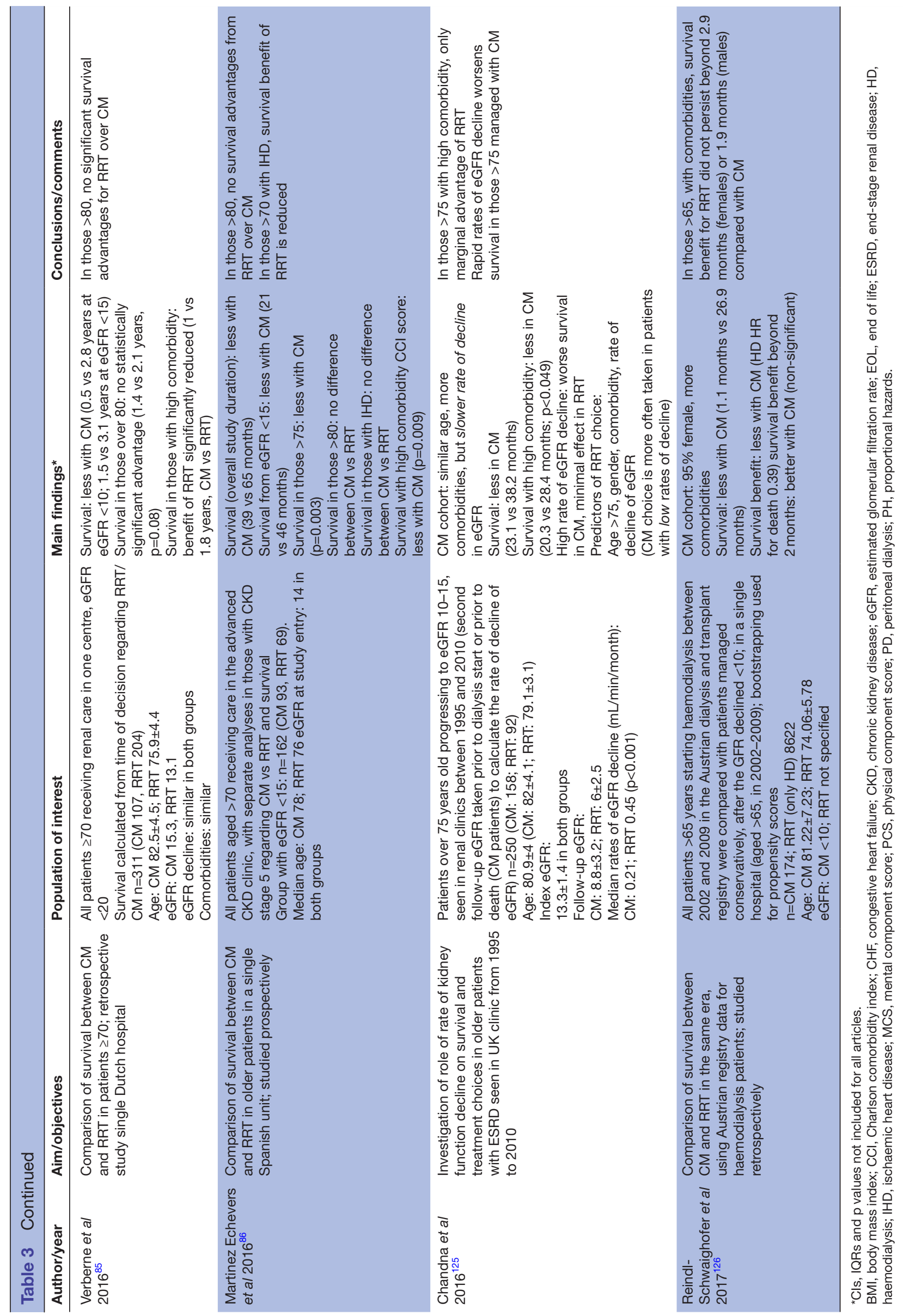


Table 4 Factors affecting quality of life

\section{Potentially modifiable} factors

\begin{tabular}{|c|c|}
\hline Physical status & Age \\
\hline Functional decline & Gender \\
\hline Frailty & Race \\
\hline Symptom burden & Socioeconomic status \\
\hline $\begin{array}{l}\text { Unplanned dialysis starts } \\
\text { Depression }\end{array}$ & $\begin{array}{l}\text { (some aspects amenable to } \\
\text { interventions) }\end{array}$ \\
\hline Cognitive impairment & Comorbidities (some aspects \\
\hline Positive social relationships & amenable to interventions) \\
\hline $\begin{array}{l}\text { Sleep disturbances } \\
\text { Impaired nutrition }\end{array}$ & Years spent on dialysis \\
\hline Cardiovascular health & \\
\hline $\begin{array}{l}\text { Dialysis-related factors } \\
\text { (session length, regimens, } \\
\text { etc) }\end{array}$ & \\
\hline
\end{tabular}

falls). Discussions of decision-making, survival and ageing were also common.

Older patients reported difficulties in getting information, feeling disempowered and dominated by the healthcare team and not being part of decisions. ${ }^{41}$ Patients reporting disempowerment were more likely to regret the decision to go onto dialysis; this was more common if they started dialysis due to family compulsions. ${ }^{42}$ Patients wanted greater involvement in deciding practical aspects of dialysis such as dry weight, the time of treatment, dietary restrictions or the access to use for dialysis. ${ }^{41}$

Coping and adaptation to treatment were important parts of the narrative. Successful coping was vital. ${ }^{43}$ Patients that coped successfully had "a transformed care dynamic, positive appraisal and active everyday engagement". ${ }^{44}$ Useful coping strategies included letting go, overcoming, keeping a sense of humour, looking at the good side of things and thinking positively. ${ }^{456}$

The incurability of kidney failure forces patients to reinvent themselves, make compromises or adopt beliefs or behaviours discordant with medical opinion. ${ }^{47-50}$ Despite these burdens, the majority of patients reported satisfaction with treatment and improvement of symptoms; another study found that the majority of patients reported no decision regret or ambivalence about starting dialysis. ${ }^{51} 52$ It should be noted, however, that patients' decisions, goals and expectations are not static but change with time as different issues emerge. ${ }^{42} 53$

Patients constantly reflect on themselves in relation to others-being a burden, receiving help or having other relationships. ${ }^{484}$ Partnership was frequently mentioned, whether spousal or with professionals. ${ }^{44}{ }^{55}$ Patients reported close and supportive relationships with healthcare professionals in some centres; dialysis nurses often encouraged patients to be independent and assisted with coping. ${ }^{52}$ Otherwise, elders reflected on the busy cultures of units, with infrequent opportunities to speak to doctors. ${ }^{56}$
Several included studies referred to the effects of dialysis on the functional status of older patients, particularly in the first 6 months where up to $30 \%$ face decline. ${ }^{57-59}$ This is even worse in patients living in nursing homes where $61 \%$ declined in functional status or died within the first 3 months; this figure was $87 \%$ at 1 year. ${ }^{60}$ Falls are common, particularly soon after dialysis. ${ }^{61}$

The symptom burden was high, and this was confirmed by qualitative studies which provided stories of suffering and burden inflicted by dialysis. ${ }^{62}$ Despite this, scores of mental components of quality of life and satisfaction with life appear to be stable and equal to or better than that for younger patients. ${ }^{33}$ Other correlates of a good quality of life in these studies included living with family rather than alone or in a nursing home and having widespread social relationships. The social well-being of older dialysis patients did not decline significantly with time. ${ }^{63}{ }^{64}$ Physical scores were uniformly lower. ${ }^{60656}$ There were several interactions among these factors, such as those between cognition and depression, physical decline and risk of falling and insomnia and depression. ${ }^{6768}$ Octogenarians were frequently hospitalised for infections; while those patients who had access to a conservative management pathway were less likely to be admitted to hospital, particularly at the end of life. ${ }^{40} 69$

Older patients are aware of impending mortality and frequently contemplate death. ${ }^{70}$ These topics are difficult to talk about. ${ }^{71}$ The haemodialysis machine is seen as a lifeline as it attempts to relieve suffering even though dialysis can be seen as a prison, or between life and death. ${ }^{41454}$ Thoughts of stopping dialysis arise oftenincreasing age, female gender, dementia and prior cerebral vascular disease are risk factors for withdrawal. ${ }^{72} 73$

\section{Characteristics of studies reporting on information needs of the older patient}

A total of 32 articles, mostly published in the last 10 years, were concerned with information needs of older patients with advanced kidney failure. Seventeen articles were original research papers, eight were opinion pieces and six were reviews (predominantly narrative reviews). Most research was in the qualitative realm (12/17 interviews and focus groups analysis; 4/17 survey-based analysis).

\section{Content and scope of studies reporting on information needs in the older patient}

Thematic analysis of the included studies revealed the broad themes which are summarised in figure 3 . The most frequently reported theme related to the need for complete information about treatment modalities, including non-dialysis pathways. Such information is not uniformly provided to patients-discussion about conservative care options, for instance, was more likely to happen if the particular renal unit had an established conservative treatment pathway. ${ }^{8}$

With a perceived uncertainty regarding kidney disease and its treatment requirements, patients desired information about kidney disease, progression and the symptoms 


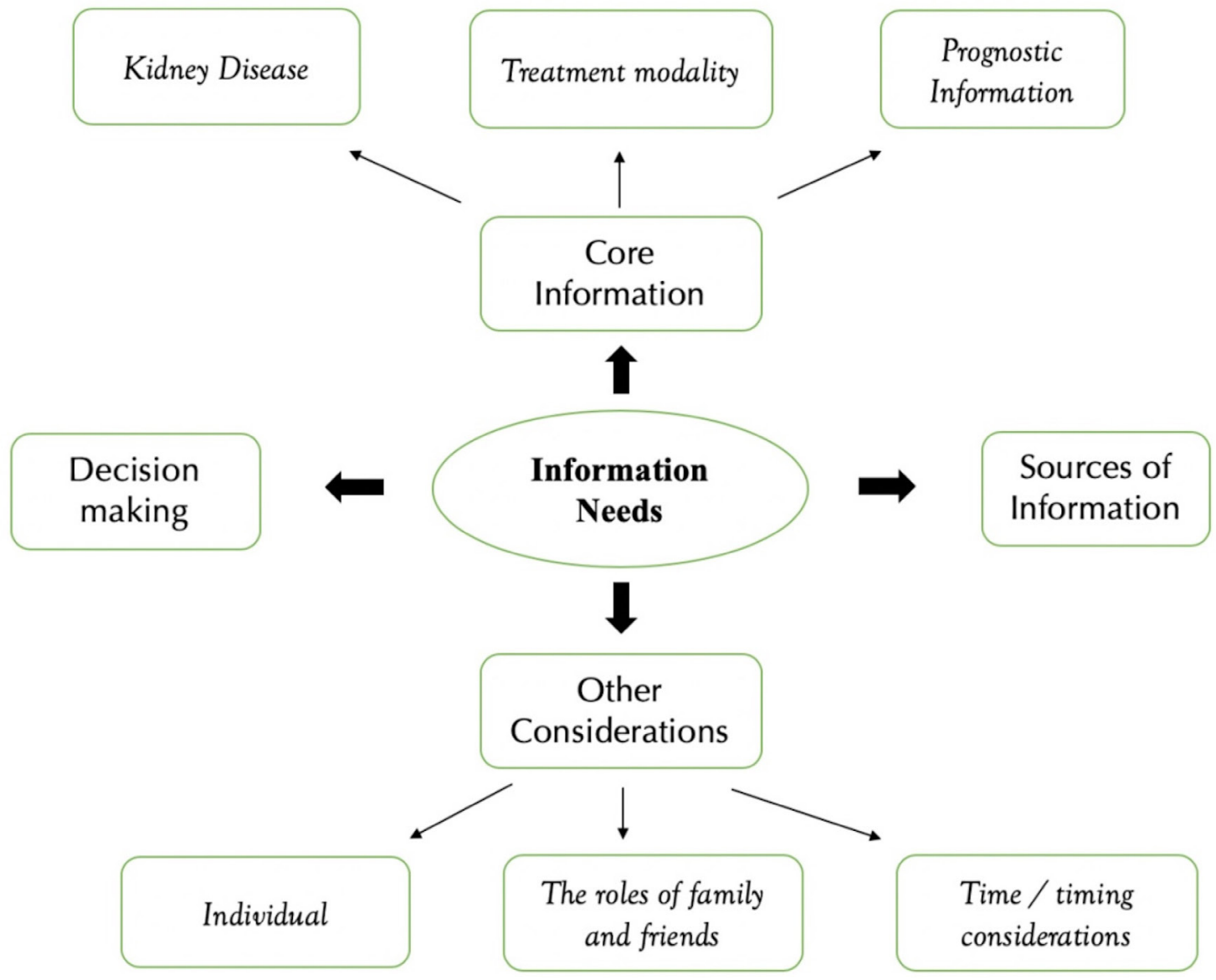

Figure 3 Information needs - themes elicited.

that may arise, especially with non-dialysis pathways of treatment. Even though survival was an important aspect of prognosis, of relevance to patients, they often report not receiving information regarding this. Clinicians are hesitant or unwilling to discuss prognosis for many reasons (uncertainty, not wanting to take away hope, etc) ${ }^{7}$ Yet, this is vital information which could affect the choices patients make about therapy. Fine and colleagues, in two separate questionnaire-based studies on predialysis populations, showed that patients expect doctors to give them prognostic information even without being prompted. ${ }^{1011}$

Mortality, and thoughts about dying, were very common, especially in those considering conservative treatment or discontinuation of dialysis. Some patients were reticent to engage with the topic of discontinuation and death because they found themselves overwhelmed, and continued dialysis even without making a deliberate choice to do so-they did not want to think about other options since they knew that death was certain without dialysis. ${ }^{74}$ The frequent discussion of mortality and consideration of future care by older patients suggest that they will be amenable to advance care planning discussions.

Information needs and dialysis decisions are a fluid process, subject to change for most patients. ${ }^{75}$ With apparently limited choices, the alternative to dialysis appeared to be death. ${ }^{76}$ Patients welcomed the opportunity to participate in shared decision-making but regretted the 'pressure' they felt from the clinical team for a decision. ${ }^{77}$ They sought information on the outcomes if they did not have dialysis or withdrew from treatment. ${ }^{74}$ In general, they requested information pertinent to the older patient and reflective of patient-centred values and considerations. ${ }^{78}$ Patients had their own estimates about the importance of quality of life or survival on dialysis rather than the perceived benefits of treatment. ${ }^{78-80}$ As expected, patients had different preferred learning styles-for instance, some preferred visual aids or written information rather than verbal. It was important that information be presented in small chunks, in simple rather than complex terms and avoiding medical jargon. ${ }^{81}$

Several practical issues were important to patients. These included information on the need for lifestyle, diet or fluid intake changes, travel, hospital visits, anticipated support needs and availability of support services in the community. ${ }^{82}$

\section{DISCUSSION}

Older patients with kidney failure turn to their clinicians-nephrologists, renal nurses, educators and other allied health staff-to discuss their choices of treatment. This scoping review attempted to summarise the 
published information that is available for use by clinicians for these discussions.

An important consideration is that of prognosis with treatment. The majority of articles addressing prognosis focused on mortality as an outcome. The risks of further progression of renal impairment and development of end-stage kidney disease are also relevant to prognosis. Table 2 lists multiple validated prognostic indices created from combining multiple predictors to estimate either mortality or risk of progression to end-stage kidney disease in older patients. Use of these indices have been recommended as an important part of the shared decision-making process. ${ }^{22} 8384$

The studies summarised in table 3, contrasting dialysis care with non-dialysis conservative management, are a reminder that specific consideration ought to be given to discussions of prognosis since this information could influence treatment choice. Advancing age has its own prognostic import which needs to be considered separately from other factors. ${ }^{12}$ Older patients, especially those with multiple comorbidities, may not derive the same survival benefit from being on dialysis as their younger counterparts. ${ }^{69} 8586$ We recommend the use of tools and models developed specifically in older individuals to estimate the risks of mortality and the risks of progressing to end-stage kidney disease since there are practical implications in this age group. For instance, patients with a high risk of mortality and a low risk of progression to end-stage kidney disease may be better suited to a non-dialysis, conservative treatment pathway. ${ }^{84}$

When elders discuss treatments such as dialysis, they face the prospect of significant changes to their lifestyle, and therefore there is often a consideration of the resultant quality of life (often rated equally important as 'quantity', or longevity). A conservative pathway of care, especially if this aligns well with patients' values, could potentially offer better or equal quality-of-life experience when compared with dialysis. ${ }^{35} 3787$ Other factors merit consideration-such as the reduced odds of hospitalisation on a conservative pathway or the greater likelihood that with this pathway, patients were more likely to die in a place of their choice or receive palliative care before their death. ${ }^{15} 35366988-90$ It is worthwhile remembering, however, that within the literature, conservative management has mostly been compared with routine dialysis modalities such as thrice-weekly in-centre haemodialysis. Dialysis treatment can be potentially modified to suit the needs of older, frailer individuals-such as by the provision of assisted peritoneal dialysis or reduced frequency of haemodialysis sessions. In a recent paper by Iyasere $e t$ $a l$, it was shown that when patients were provided with assistance in performing peritoneal dialysis at home, they achieved quality-of-life scores that were better than a contemporaneous cohort of conservatively managed patients. ${ }^{91}$ The comparisons between particular modalities of treatment become relevant once the patient makes the choice to have dialysis-however, they were not within the scope of this review. It must be acknowledged that the local availability of treatments tailored to the older patient may influence treatment choice. If such modified treatments can be offered, then this information, including the potential benefits and compromises, ought to be presented to patients.

There is a paucity of original research on the quality of life and the (potentially modifiable) factors that affect quality of life, as also evidenced by a 2017 systematic review. ${ }^{92}$ Included studies (29 detailing clinical research) suggests that age, gender, physical status, comorbidities, cognition and psychological variables such as depression affected quality-of-life outcomes in older patients. ${ }^{82} 848791$ Our review identified a few potentially modifiable factors that could improve quality of life in elders considering dialysis. As shown in table 4, some of these factors, such as depression, sleep disturbances or poor nutrition, may be amenable to intervention in the pre-dialysis stage itself. Brown suggests that engaging patients in discussion, emphasising lifestyle effects of treatment, considering benefits of all interventions-even renal clinic visitsare additional measures to improve quality of life in elders with advanced chronic kidney disease. ${ }^{82}$ If specific measures can be instituted to improve the quality-of-life experiences of patients in various pathways, the differences in patient-reported experiences may be much less significant-this is a developing area of clinical practice and research. ${ }^{91} 9394$

We anticipated that the reports of the lived experience of previous older patients on dialysis would offer valuable insights for those now considering options. Our review suggests that while some patients were able to cope successfully and 'reinvent themselves' in their new lives, others described negative outcomes. ${ }^{59}$ The lived experience of such patients is dominated by disempowerment, lack of knowledge, cognitive impairment, depression, difficulties with strict regulations regarding diet, fluid and dialysis timings, and finally, functional decline, which called into question their relationships with family and made them feel a burden to others. Such descriptions should prompt clinicians to ensure that older patients receive appropriate information about potential lifestyle changes prior to starting - this will also mitigate the reports of regret at having started dialysis. ${ }^{51} 9596$

Patients' relationships-personal and professionalplay an important role. Multiple social connections and close family relationships appear to improve the experience of dialysis. Healthcare professionals, as expected, play important roles in these patients' lives, which extends beyond the initial provision of information for discussion. The reports of functional and cognitive decline suggest that clinicians should inform potential patients of these risks and also periodically measure physical status, functional impairment and cognitive status so that appropriate interventions can be planned early. ${ }^{9397}$ Qualitative studies in this population frequently involve discussions of death and mortality, suggesting the importance of discussions regarding end-of-life care or advance care directives early in the patient course. 
Table 5 Implications for practice

\begin{tabular}{|c|c|c|}
\hline Domains to consider & Practical steps & Expected benefit in older adults \\
\hline $\begin{array}{l}\text { Making information easy to grasp for } \\
\text { the older person }\end{array}$ & $\begin{array}{l}\text { Specifically, in older individuals, } \\
\text { consider how information is provided: } \\
\text { avoid medical jargon, make allowances } \\
\text { for cognitive impairment and depression }\end{array}$ & $\begin{array}{l}\text { Promotes health awareness } \\
\text { Strengthens decision-making } \\
\text { Mitigates regret after starting treatment }\end{array}$ \\
\hline Involvement of carers/family/friends & $\begin{array}{l}\text { Proactively identify relevant carers } \\
\text { especially in frail, dependent elders and } \\
\text { include them in discussions or when } \\
\text { planning support }\end{array}$ & $\begin{array}{l}\text { Promotes carer involvement which is } \\
\text { important to older patients } \\
\text { Mitigates carer burden }\end{array}$ \\
\hline $\begin{array}{l}\text { Risk of disease progression to end- } \\
\text { stage kidney disease }\end{array}$ & $\begin{array}{l}\text { Use prognostic indices developed in } \\
\text { the older population to provide realistic } \\
\text { estimates of disease progression (see } \\
\text { table 2) }\end{array}$ & $\begin{array}{l}\text { Identifies patients less likely to progress and } \\
\text { more suited for supportive measures at that } \\
\text { particular time }\end{array}$ \\
\hline Survival with end-stage kidney disease & $\begin{array}{l}\text { Use prognostic indices developed in } \\
\text { the older population to provide realistic } \\
\text { estimates of survival (see table 2) }\end{array}$ & $\begin{array}{l}\text { Fosters realistic expectations of survival } \\
\text { benefit }\end{array}$ \\
\hline $\begin{array}{l}\text { Lessons from the experiences of other } \\
\text { older people }\end{array}$ & $\begin{array}{l}\text { Counsel patients regarding lifestyle } \\
\text { changes; functional worsening; impact } \\
\text { on daily life, relationships; persistent } \\
\text { symptom burden; time commitments; } \\
\text { need for coping strategies }\end{array}$ & \\
\hline
\end{tabular}

Finally, we surveyed the literature on patients' information needs. Patients are interested in their prognosis (survival, eventual outcome) with and without dialysis treatment. ${ }^{4}$ However, decision-making for patients, carers and their healthcare professionals does not rely merely on survival statistics. ${ }^{82}$ There is specific interest in the impact of dialysis on personal outcomes such as quality of life. ${ }^{101176809598}$ Older patients already on dialysis tell us that they would have liked more practical knowledge about what is actually involved in having dialysis, as well as the effects of dialysis on daily life. Matters relevant to older patients ought to be presented in a non-technical, jargon-free manner, with patient participation, and giving them 'more rather than less'. Our review did not address the methods of provision of information.

The information needs of patients summarised above are of central importance in discussions of treatment. Although these included articles capture the patient perspective, it would be beneficial for future researchers to seek patient and public involvement even during the initial design of questions for a review. Such early involvement could potentially highlight more gaps in the literature that addresses patient needs.

\section{Practical implications}

Older patients are a unique group and clinicians preparing to counsel them about treatment choices ought to prepare deliberately. Table 5 lists a few practical steps for the clinical team to consider based on the domains uncovered in our scoping review. The primary aim of this discussion is to help patients make appropriate choices, with realistic expectations of benefits from treatment and a good understanding of the changes in lifestyle occasioned by the treatment.

It is worthwhile to consider how the information from this scoping review may be used within recommended frameworks for communication and decision-making in this patient group. Schell and Cohen suggested the SPIRES framework (the acronym SPIRES standing for set-up, perceptions and perspectives, invitation, recommendation, empathise, summarise and strategise) to help patients weigh up the benefits and risks of dialysis. ${ }^{99}$ Similarly, Rosansky and colleagues suggested a framework incorporating clinical and patient considerations in arriving at a shared decision. ${ }^{100}$ Figure 4 suggests how available information as summarised in this scoping review can be used to guide decisions as these frameworks are applied.

In this review, we did not address how this information ought to be presented to patients. This is a crucial area of research, as there needs to be enquiry into the appropriate method of educating older patients as opposed to younger cohorts. Subsequently, the effectiveness of these 


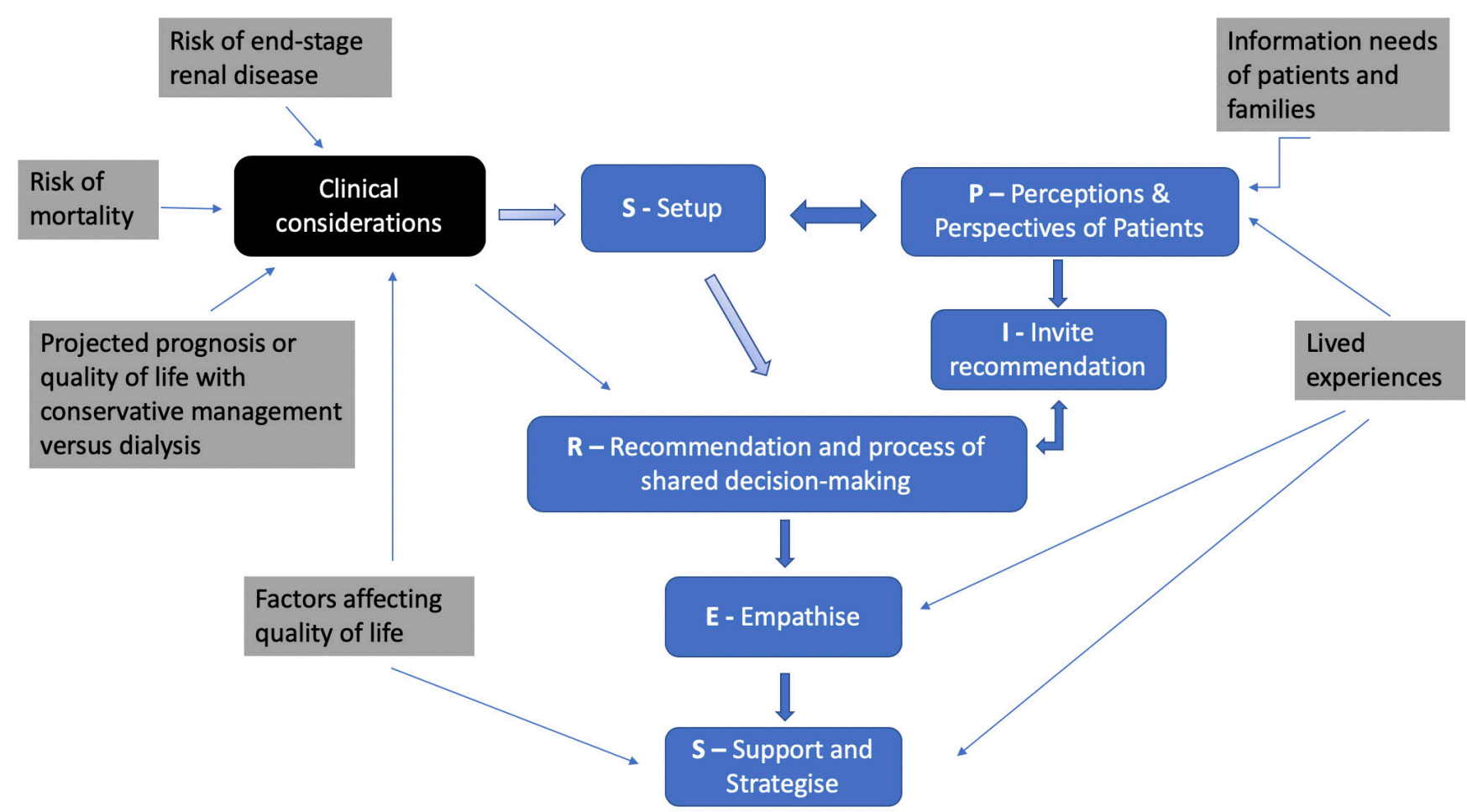

Figure 4 Using available information in a framework for decision-making. Adapted from Schell and Cohen ${ }^{99}$ and Rosansky et al. ${ }^{100}$ Grey text boxes: information available to guide decisions. Bold arrows: suggested steps in the frameworks. Light arrows: influences.

interventions and this shared decision-making process need to be studied. Patient-reported outcome measures such as quality of life, satisfaction with care or absence of decisional conflict may reflect on the success of the process. ${ }^{101-103}$ Other indicators may include indirect evidence such as the proportion of patients withdrawing from treatment pathways after initial selection or starting treatment. These and other areas for future research are highlighted in box 1 below.

\section{CONCLUSION}

Not all older patients progress to end-stage kidney failure, and clinicians can use scores that predict the risk of this

\section{Box 1 Areas for future research}

1. Prediction of outcomes other than survival (eg, quality of life, functional decline).

2. Factors influencing quality of life in older patients (and the effects of modifying these factors).

3. Modifications of treatment to support older individuals (assisted peritoneal dialysis, incremental dialysis, etc) and their effects on patient choices and outcomes.

4. Improving the communication of information, and monitoring delivery and understanding.

5. Studies of the effectiveness of the shared decision-making process in older patients with kidney disease.

6. Interventions to promote carer education and support. progression, so that discussions and plans are conducted appropriately to the patient's expected course. For those older patients who reach end-stage kidney failure, length of survival is an important consideration when comparing dialysis treatment to conservative care, particularly if there are multiple comorbidities. Clinicians now have several validated indices to help with prognostication. However, as evident from this scoping review, longevity or survival are not the only factors patients and families take into account-there are other expectations of treatment, such as the anticipated quality of life or functional status. Some factors influencing quality of life are modifiable. The study of lived experiences of dialysis in older people informs us of the requirements for patients to adapt to their new realities, and the problems from functional deterioration, dependency and persistent symptoms. Patients should be forewarned about these potential outcomes and preventive measures considered. All information ought to be presented in a manner that the older patient can easily understand, retain and apply. Further research is needed into quality-of-life outcomes in older individuals, methods of efficient communication of information and assessment of the success of shared decision-making.

Twitter Rajesh Raj @kidneymedic and Mai Frandsen @FrandsenMai

Contributors RR is the primary and corresponding author for the first and all subsequent drafts. RR and KDKA were responsible for initial discussion. RR, KDKA, MF and MJ were involved in subsequent discussion and design of the 
study protocol. RR and ST performed the study selection process independently. All five authors contributed to the design of the work, revised the drafts critically for content and approved the final version to be published. All authors agree to be accountable for all aspects of the work in ensuring that questions related to the accuracy or integrity of any part of the work are appropriately investigated and resolved.

Funding The authors have not declared a specific grant for this research from any funding agency in the public, commercial or not-for-profit sectors.

Competing interests None declared.

Patient consent for publication Not required

Provenance and peer review Not commissioned; externally peer reviewed.

Data availability statement All data relevant to the study are included in the article or uploaded as online supplementary information.

Open access This is an open access article distributed in accordance with the Creative Commons Attribution Non Commercial (CC BY-NC 4.0) license, which permits others to distribute, remix, adapt, build upon this work non-commercially, and license their derivative works on different terms, provided the original work is properly cited, appropriate credit is given, any changes made indicated, and the use is non-commercial. See: http://creativecommons.org/licenses/by-nc/4.0/.

\section{ORCID IDs}

Rajesh Raj http://orcid.org/0000-0003-4781-3255

Srivathsan Thiruvengadam http://orcid.org/0000-0002-2678-6190

Kiran Deep Kaur Ahuja http://orcid.org/0000-0002-0323-4692

Mai Frandsen http://orcid.org/0000-0001-7027-1445

\section{REFERENCES}

1 Iwashyna TJ, Christakis NA. Physicians, patients, and prognosis. West J Med 2001;174:253-4.

2 Mack JW, Smith TJ. Reasons why physicians do not have discussions about poor prognosis, why it matters, and what can be improved. JCO 2012;30:2715-7.

3 Ladin K, Pandya R, Kannam A, et al. Discussing conservative management with older patients with CKD: an interview study of nephrologists. Am J Kidney Dis 2018;71:627-35.

4 Mandel El, Bernacki RE, Block SD. Serious illness conversations in ESRD. CJASN 2017;12:854-63.

5 Parvez S, Abdel-Kader K, Song M-K, et al. Conveying uncertainty in prognosis to patients with ESRD. Blood Purif 2015;39:58-64.

6 Singh P, Germain MJ, Cohen L, et al. The elderly patient on dialysis: geriatric considerations. Nephrol Dial Transplant 2014;29:990-6.

7 Schell JO, Patel UD, Steinhauser KE, et al. Discussions of the kidney disease trajectory by elderly patients and nephrologists: a qualitative study. Am J Kidney Dis 2012;59:495-503.

8 Tonkin-Crine S, Okamoto I, Leydon GM, et al. Understanding by older patients of dialysis and conservative management for chronic kidney failure. Am J Kidney Dis 2015;65:443-50.

9 Wachterman MW, Marcantonio ER, Davis RB, et al. Relationship between the prognostic expectations of seriously ill patients undergoing hemodialysis and their nephrologists. JAMA Intern Med 2013:173:1206-14.

10 Fine A, Fontaine B, Kraushar MM, et al. Nephrologists should voluntarily divulge survival data to potential dialysis patients: a questionnaire study. Perit Dial Int 2005;25:269-73.

11 Fine A, Fontaine B, Kraushar MM, et al. Patients with chronic kidney disease stages 3 and 4 demand survival information on dialysis. Perit Dial Int 2007;27:589-91.

12 Schmidt RJ. Informing our elders about dialysis: is an age-attuned approach warranted? CJASN 2012;7:185-91.

13 O'Hare AM, Choi Al, Bertenthal D, et al. Age affects outcomes in chronic kidney disease. JASN 2007;18:2758-65.

14 Verberne WR, Dijkers J, Kelder JC, et al. Value-based evaluation of dialysis versus conservative care in older patients with advanced chronic kidney disease: a cohort study. BMC Nephrol 2018;19:205.

15 O'Connor NR, Kumar P. Conservative management of end-stage renal disease without dialysis: a systematic review. J Palliat Med 2012;15:228-35.

16 Susanto C, Kooman J, Courtens AM, et al. Conservative care as a treatment option for patients aged 75 years and older with CKD stage V: a national survey in the Netherlands. Eur Geriatr Med 2018;9:235-42.

17 van de Luijtgaarden MWM, Noordzij M, van Biesen W, et al. Conservative care in Europe-nephrologists' experience with the decision not to start renal replacement therapy. Nephrol Dial Transplant 2013;28:2604-12

18 Okamoto I, Tonkin-Crine S, Rayner $\mathrm{H}$, et al. Conservative care for ESRD in the United Kingdom: a national survey. CJASN 2015;10:120-6.

19 Morton RL, Turner RM, Howard K, et al. Patients who plan for conservative care rather than dialysis: a national observationa study in Australia. Am J Kidney Dis 2012;59:419-27.

20 Berger JR, Jaikaransingh V, Hedayati SS. End-Stage kidney disease in the elderly: approach to dialysis initiation, choosing modality, and predicting outcomes. Adv Chronic Kidney Dis 2016;23:36-43.

21 Moss $\mathrm{AH}$. Revised dialysis clinical practice guideline promotes more informed decision-making. Clin J Am Soc Nephrol 2010;5:2380-3.

22 Brown MA, Crail SM, Masterson R, et al. ANZSN renal supportive care 2013: opinion pieces [corrected]. Nephrology 2013;18:401-54.

23 Parvez S, Abdel-Kader K, Pankratz VS, et al. Provider knowledge, attitudes, and practices surrounding conservative management for patients with advanced CKD. Clin J Am Soc Nephrol 2016;11:812-20.

24 Tangri Net al. A predictive model for progression of chronic kidney disease to kidney failure. JAMA 2011;305:1553-9.

25 Cheung KL, Montez-Rath ME, Chertow GM, et al. Prognostic stratification in older adults commencing dialysis. J Gerontol A Biol Sci Med Sci 2014;69:1033-9.

26 Collins GS, Omar O, Shanyinde M, et al. A systematic review finds prediction models for chronic kidney disease were poorly reported and often developed using inappropriate methods. J Clin Epidemiol 2013;66:268-77.

27 Rigatto C, Sood MM, Tangri N. Risk prediction in chronic kidney disease: pitfalls and caveats. Curr Opin Nephrol Hypertens 2012;21:612-8.

28 Tricco AC, Lillie E, Zarin W, et al. PRISMA extension for scoping reviews (PRISMA-ScR): checklist and explanation. Ann Intern Med 2018;169:467-73.

29 Raj R, Ahuja KDK, Frandsen M, et al. Older patient considering treatment for advanced renal disease: protocol for a scoping review of the information available for shared decision-making. BMJ Open 2016:6:e013755.

30 The Joanna Briggs Institute. Joanna Briggs Institute Reviewers' Manual: Methodology for JBI Scoping Reviews. The Joanna Briggs Institute, 2015.

31 Ouzzani M, Hammady H, Fedorowicz Z, et al. Rayyan-a web and mobile app for systematic reviews. Syst Rev 2016;5:210.

32 Viera AJ, Garrett JM. Understanding interobserver agreement: the kappa statistic. Fam Med 2005;37:360-3.

33 Unruh ML, Newman AB, Larive B, et al. The influence of age on changes in health-related quality of life over three years in a cohort undergoing hemodialysis. J Am Geriatr Soc 2008;56:1608-17.

34 Moura A, Madureira J, Alija P, et al. Effect of aging in the perception of health-related quality of life in end-stage renal disease patients under. Aging Dis 2015;6:17-26.

35 Brown MA, Collett GK, Josland EA, et al. CKD in elderly patients managed without dialysis: survival, symptoms, and quality of life. CJASN 2015;10:260-8.

36 Lægreid IK, Aasarød K, Bye A, et al. The impact of nutritional status, physical function, comorbidity and early versus late start in dialysis on quality of life in older dialysis patients. Ren Fail 2014;36:9-16.

37 Ch'ng AS, Chen LL, Lim SK, et al. Haemodialysis versus nondialysis therapy among older adults with stage 5 chronic kidney disease: a comparison of health-related quality of life. Value in Health 2015;18.

38 De Pasquale C, Pistorio ML, Corona D, et al. Correlational study between psychic symptoms and quality of life among hemodialysis patients older than 55 years of age. Transplant Proc 2012;44.

39 Kesikburun Y. Determinants of health-related quality of life in elderly hemodialysis patients. Turkish Journal of Geriatrics 2017;20:204-12.

40 Sun Y, Kassam H, Adeniyi M, et al. Hospital admissions in elderly patients on chronic hemodialysis. Int Urol Nephrol 2011;43:1229-36.

41 Aasen EM, Kvangarsnes M, Heggen K. Perceptions of patient participation amongst elderly patients with end-stage renal disease in a dialysis unit. Scand J Caring Sci 2012;26:61-9.

42 Stringer S, Baharani J. Why did I start dialysis? A qualitative study on views and expectations from an elderly cohort of patients with end-stage renal failure starting haemodialysis in the United Kingdom. Int Urol Nephrol 2012;44:295-300.

43 Llewellyn H, Low J, Smith G, et al. Narratives of continuity among older people with late stage chronic kidney disease who decline dialysis. Soc Sci Med 2014;114:49-56. 
44 Namiki S, Rowe J, Cooke M. Living with home-based haemodialysis: insights from older people. J Clin Nurs 2010;19:547-55.

45 de Guzman AB, Chy MAS, Concepcion AFP, et al. The language of coping: understanding Filipino geriatric patients' hemodialysis lived experiences. Educ Gerontol 2009;35:769-83.

46 Logan SM, Pelletier-Hibbert M, Hodgins M. Stressors and coping of in-hospital haemodialysis patients aged 65 years and over. J Adv Nurs 2006;56:382-91.

47 Russ ANNJ, Shim JK, Kaufman SR. "Is there life on dialysis?". time and aging in a clinically sustained existence. Med Anthropol 2005;24:297-324.

48 Walker R, James H, Burns A. Adhering to behaviour change in older pre-dialysis populations - what do patients think? A qualitative study. J Ren Care 2012;38:34-42.

49 Rifkin DE, Laws MB, Rao M, et al. Medication adherence behavior and priorities among older adults with CKD: a semistructured interview study. Am J Kidney Dis 2010;56:439-46.

50 Bowling CB, Vandenberg AE, Phillips LS, et al. Older patients perspectives on managing complexity in CKD self-management. CJASN 2017;12:635-43.

51 Tan EGF, Teo I, Finkelstein EA, et al. Determinants of regret in elderly dialysis patients. Nephrology 2019;24:622-9.

52 Derrett S, Darmody M, Williams S, et al. Older peoples' satisfaction with home-based dialysis. Nephrology 2010;15:464-70.

53 Elliott MJ, Tam-Tham H, Hemmelgarn BR, et al. Age and treatment of kidney failure. Curr Opin Nephrol Hypertens 2013;22:344-50.

54 Hagren B, Pettersen I-M, Severinsson E, et al. The haemodialysis machine as a lifeline: experiences of suffering from end-stage renal disease. J Adv Nurs 2001;34:196-202.

55 Petersson I, Lennerling A. Experiences of living with assisted peritoneal dialysis - a qualitative study. Perit Dial Int 2017;37:605-12.

56 Bristowe K, Horsley HL, Shepherd K, et al. Thinking ahead-the need for early advance care planning for people on haemodialysis: a qualitative interview study. Palliat Med 2015;29:443-50.

57 Jassal SV, Watson D. Dialysis in late life: benefit or burden. CJASN 2009;4:2008-12.

58 Račić M, Petković N, Bogićević K, et al. Comprehensive geriatric assessment: comparison of elderly hemodialysis patients and primary care patients. Ren Fail 2015;37:1126-31.

59 Desmet C, Beguin C, Swine C, et al. Falls in hemodialysis patients: prospective study of incidence, risk factors, and complications. Am $J$ Kidney Dis 2005;45:148-53.

60 Kurella Tamura M, Covinsky KE, Chertow GM, et al. Functional status of elderly adults before and after initiation of dialysis. $N$ Engl $J$ Med 2009;361:1539-47.

61 Magnard J, Lardy J, Testa A, et al. The effect of hemodialysis session on postural strategies in older end-stage renal disease patients. Hemodial Int 2015;19:553-61.

62 Seah AST, Tan F, Srinivas S, et al. Opting out of dialysis-exploring patients' decisions to forego dialysis in favour of conservative nondialytic management for end-stage renal disease. Health Expect 2015;18:1018-29.

63 Seckinger J, Dschietzig W, Leimenstoll G, et al. Morbidity, mortality and quality of life in the ageing haemodialysis population: results from the ELDERLY study. Clin Kidney J 2016;9:839-48.

64 Kutner NG, Jassal SV. Quality of life and rehabilitation of elderly dialysis patients. Semin Dial 2002;15:107-12.

65 Brown EA. Peritoneal dialysis for older people: overcoming the barriers. Kidney Int 2008;73:S68-71.

66 Tattersall J. Dialysis in the over-80s. Age Ageing 2005;34:100-1.

67 Kutner NG, Brogan D, Hall WD, et al. Functional impairment, depression, and life satisfaction among older hemodialysis patients and age-matched controls: a prospective study. Arch Phys Med Rehabil 2000;81:453-9.

68 Tyrrell J, Paturel L, Cadec B, et al. Older patients undergoing dialysis treatment: cognitive functioning, depressive mood and health-related quality of life. Aging Ment Health 2005;9:374-9.

69 Hussain JA, Mooney A, Russon L. Comparison of survival analysis and palliative care involvement in patients aged over 70 years choosing conservative management or renal replacement therapy in advanced chronic kidney disease. Palliat Med 2013;27:829-39.

70 Axelsson L, Randers I, Lundh Hagelin C, et al. Thoughts on death and dying when living with haemodialysis approaching end of life. $J$ Clin Nurs 2012;21:2149-59.

71 Makaroff KLS, Sheilds L, Molzahn A. Stories of chronic kidney disease: listening for the unsayable. J Adv Nurs 2013;69:2644-53.

72 Findlay MD, Donaldson K, Doyle A, et al. Factors influencing withdrawal from dialysis: a national registry study. Nephrol. Dial. Transplant. 2016;31:2041-8.
73 lkäheimo R, Kervinen M, Karhapää P, et al. Discontinuation of dialysis treatment: experience of a single dialysis centre. Scand $J$ Urol Nephrol 2005;39:417-22.

74 Russ AJ, Kaufman SR. Discernment rather than decision-making among elderly dialysis patients. Semin Dial 2012;25:31-2.

75 Lovell S, Walker RJ, Schollum JBW, et al. To dialyse or delay: a qualitative study of older New Zealanders' perceptions and experiences of decision-making, with stage 5 chronic kidney disease. BMJ Open 2017;7:e014781.

76 Harwood L, Clark AM. Understanding pre-dialysis modality decision-making: a meta-synthesis of qualitative studies. Int J Nurs Stud 2013;50:109-20.

77 Loiselle M-C, Michaud C, O'Connor A. Decisional needs assessment to help patients with advanced chronic kidney disease make better dialysis choices. Nephrol Nurs $J$ 2016;43:463-93.

78 Moustakas J, Bennett PN, Nicholson J, et al. The needs of older people with advanced chronic kidney disease choosing supportive care: a review. Renal Society of Australasia Journal 2012;8:70-5.

79 Elliott BA, Gessert CE, Larson PM, et al. Shifting responses in quality of life: people living with dialysis. Qual Life Res 2014;23:1497-504.

80 Hussain JA, Flemming K, Murtagh FEM, et al. Patient and health care professional decision-making to commence and withdraw from renal dialysis: a systematic review of qualitative research. Clin J Am Soc Nephrol 2015;10:1201-15.

81 Koncicki HM, Schell JO. Communication skills and decision making for elderly patients with advanced kidney disease: a guide for nephrologists. Am J Kidney Dis 2016;67:688-95.

82 Burns A, Davenport A. Maximum conservative management for patients with chronic kidney disease stage 5. Hemodial Int 2010;14:S32-7

83 Moss $\mathrm{AH}$. Shared decision-making in dialysis: the new RPA/ASN guideline on appropriate initiation and withdrawal of treatment. Am J Kidney Dis 2001;37:1081-91.

84 Farrington K, Covic A, Nistor I, et al. Clinical practice guideline on management of older patients with chronic kidney disease stage 3B or higher (eGFR. Nephrol Dial Transplant 2017;32:9-16.

85 Verberne WR, Geers ABMT, Jellema WT, et al. Comparative survival among older adults with advanced kidney disease managed conservatively versus with dialysis. CJASN 2016;11:633-40.

86 Martínez Echevers Y, Toapanta Gaibor NG, Nava Pérez N, et al. Survival of patients $\geq 70$ years with advanced chronic kidney disease: dialysis vs. conservative care. Nefrología 2016;36:283-91.

87 Seow Y-Y, Cheung YB, LM Q, et al. Trajectory of quality of life for poor prognosis stage 5D chronic kidney disease with and without dialysis. Am J Nephrol 2013;37:231-8.

88 Smith C, Da Silva-Gane M, Chandna S, et al. Choosing not to dialyse: evaluation of planned non-dialytic management in a cohort of patients with end-stage renal failure. Nephron Clin Pract 2003;95:c40-6.

89 Carson RC, Juszczak M, Davenport A, et al. Is maximum conservative management an equivalent treatment option to dialysis for elderly patients with significant comorbid disease? CJASN 2009;4:1611-9.

90 Shum CK, Tam KF, Chak WL, et al. Outcomes in older adults with stage 5 chronic kidney disease: comparison of peritoneal dialysis and conservative management. J Gerontol A Biol Sci Med Sci 2014;69A:308-14.

91 Iyasere O, Brown EA, Johansson L, et al. Quality of life with conservative care compared with assisted peritoneal dialysis and haemodialysis. Clin Kidney J 2019;12:262-8.

92 Balogun SA, Balogun R, Philbrick J, et al. Quality of life, perceptions, and health satisfaction of older adults with endstage renal disease: a systematic review. J Am Geriatr Soc 2017;65:777-85.

93 Brown EA. What can we do to improve quality of life for the elderly chronic kidney disease patient? Aging health 2012;8:519-24.

94 lyasere O, Brown E, Gordon F, et al. Longitudinal trends in quality of life and physical function in frail older dialysis patients: a comparison of assisted peritoneal dialysis and in-center hemodialysis. Perit Dial Int 2019;39:112-8.

95 Berkhout-Byrne N, Gaasbeek A, Mallat MJK, et al. Regret about the decision to start dialysis: a cross-sectional Dutch national survey. Neth J Med 2017;75:225-34.

96 Gilman EA, Feely MA, Hildebrandt D, et al. Do patients receiving hemodialysis regret starting dialysis? A survey of affected patients. Clin Nephrol 2017:87 (2017:117-23.

97 Brown EA. Can quality of life be improved for the increasing numbers of older patients with end-stage kidney disease? Expert Rev Pharmacoecon Outcomes Res 2010;10:661-6. 
98 Harwood L, Clark AM. Dialysis modality decision-making for older adults with chronic kidney disease. J Clin Nurs 2014;23:3378-90.

99 Schell JO, Cohen RA. A communication framework for dialysis decision-making for frail elderly patients. Clin J Am Soc Nephrol 2014;9:2014-21.

100 Rosansky SJ, Schell J, Shega J, et al. Treatment decisions for older adults with advanced chronic kidney disease. BMC Nephrol 2017;18.

101 Alegria M, Nakash O, Johnson K, et al. Effectiveness of the decide interventions on shared decision making and perceived quality of care in behavioral health with multicultural patients: a randomized clinical trial. JAMA Psychiatry 2018;75:325-35.

102 Samalin L, Honciuc M, Boyer L, et al. Efficacy of shared decisionmaking on treatment adherence of patients with bipolar disorder: a cluster randomized trial (ShareD-BD). BMC Psychiatry 2018;18:103.

103 Davis JL, Davison SN. Hard choices, better outcomes: a review of shared decision-making and patient decision aids around dialysis initiation and conservative kidney management. Curr Opin Nephrol Hypertens 2017;26:205-13.

104 Bansal N, Katz R, De Boer IH, et al. Development and validation of a model to predict 5-year risk of death without ESRD among older adults with CKD. CJASN 2015;10:363-71.

105 Landray MJ, Emberson JR, Blackwell L, et al. Prediction of ESRD and death among people with CKD: the chronic renal impairment in Birmingham (CRIB) prospective cohort study. Am J Kidney Dis 2010;56:1082-94.

106 Drawz PE, Goswami P, Azem R, et al. A simple tool to predict endstage renal disease within 1 year in elderly adults with advanced chronic kidney disease. J Am Geriatr Soc 2013;61:762-8.

107 Chua H-R, Lau T, Luo N, et al. Predicting first-year mortality in incident dialysis patients with end-stage renal disease-the UREA5 study. Blood Purif 2014;37:85-92.

108 Wick JP, Turin TC, Faris PD, et al. A clinical risk prediction tool for 6-month mortality after dialysis initiation among older adults. $\mathrm{Am} \mathrm{J}$ Kidney Dis 2017;69:568-75.

109 Schroeder EB, Yang X, Thorp ML, et al. Predicting 5-year risk of RRT in stage 3 or 4 CKD: development and external validation. CJASN 2017;12:87-94.

110 Couchoud C, Labeeuw M, Moranne O, et al. A clinical score to predict 6-month prognosis in elderly patients starting dialysis for end-stage renal disease. Nephrol Dial Transplant 2009;24:1553-61.

111 Wagner M, Ansell D, Kent DM, et al. Predicting mortality in incident dialysis patients: an analysis of the United Kingdom renal registry. Am J Kidney Dis 2011;57:894-902.

112 Kan W-C, Wang J-J, Wang S-Y, et al. The new comorbidity index for predicting survival in elderly dialysis patients: a long-term population-based study. PLoS One 2013;8:e68748.
113 Liu J, Huang Z, Gilbertson DT, et al. An improved comorbidity index for outcome analyses among dialysis patients. Kidney Int 2010;77:141-51.

114 Dusseux E, Albano L, Fafin C, et al. A simple clinical tool to inform the decision-making process to refer elderly incident dialysis patients for kidney transplant evaluation. Kidney Int 2015;88:121-9.

115 Thamer M, Kaufman JS, Zhang Y, et al. Predicting early death among elderly dialysis patients: development and validation of a risk score to assist shared decision making for dialysis initiation. Am J Kidney Dis 2015;66:1024-32.

116 Ivory SE, Polkinghorne KR, Khandakar Y, et al. Predicting 6-month mortality risk of patients commencing dialysis treatment for end-stage kidney disease. Nephrol Dial Transplant 2017;32:gfw383-65

117 Chen L-X, Josephson MA, Hedeker D, et al. A clinical prediction score to guide referral of elderly dialysis patients for kidney transplant evaluation. Kidney Int Rep 2017;2:645-53.

118 Mauri JM, Clèries M, Vela $\mathrm{E}$, et al. Design and validation of a model to predict early mortality in haemodialysis patients. Nephrol Dial Transplant 2008;23:1690-6.

119 Floege J, Gillespie IA, Kronenberg F, et al. Development and validation of a predictive mortality risk score from a European hemodialysis cohort. Kidney Int 2015;87:996-1008.

120 Fukuma S, Shimizu S, Shintani A, et al. Development and validation of a prediction model for loss of physical function in elderly hemodialysis patients. Nephrol Dial Transplant 2018;33:1452-8.

121 Joly D, Anglicheau D, Alberti C, et al. Octogenarians reaching endstage renal disease: cohort study of decision-making and clinical outcomes. J Am Soc Nephrol 2003;14:1012-21.

122 Murtagh FEM, Marsh JE, Donohoe P, et al. Dialysis or not? A comparative survival study of patients over 75 years with chronic kidney disease stage 5. Nephrol Dial Transplant 2007;22:1955-62.

123 Chandna SM, Da Silva-Gane M, Marshall C, et al. Survival of elderly patients with stage 5 CKD: comparison of conservative management and renal replacement therapy. Nephrol Dial Transplant 2011;26:1608-14.

124 Seow Y-Y, Cheung YB, Qu LM, et al. Trajectory of quality of life for poor prognosis stage $5 \mathrm{~d}$ chronic kidney disease with and without dialysis. Am J Nephrol 2013;37:231-8.

125 Chandna SM, Carpenter L, Da Silva-Gane M, et al. Rate of decline of kidney function, modality choice, and survival in elderly patients with advanced kidney disease. Nephron 2016;134:64-72.

126 Reindl-Schwaighofer R, Kainz A, Kammer M, et al. Survival analysis of conservative vs. dialysis treatment of elderly patients with CKD stage 5. PLoS One 2017;12:e0181345. 